\title{
Role of psychology, social media, social norms and religious activity in the control of COVID-19 infection
}

\author{
Mian Adnan ${ }^{1}$, Ihsan Ali ${ }^{2}$, Bouchra Derrar ${ }^{2}$, Mujeeb ur Rahman ${ }^{2}$ \\ ${ }^{I}$ School of Life Sciences, MOE Key Laboratory of Cell Activities and Stress Adaptations, Lanzhou University, Lanzhou, China \\ ${ }^{2}$ College of Life Sciences, Northwest University, Xian, China
}

Received: 2020-08-07.

Accepted: 2020-09-14

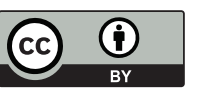

This work is licensed under a

Creative Commons Attribution 4.0

International License

\begin{abstract}
There is no reliable treatment to cure COVID-19. In the current scenario as the whole world is in a panic situation and most people are so anxious. In this situation, the way to break the chain of infection and release tension is only dependent on the friendly environment.
\end{abstract}

Key words: COVID-19, control, media, psychology, religion

\section{Introduction}

The current outbreak of COVID-19 is posing a serious health and economic problem in the whole world, even in Pakistan. Pakistan has taken certain positive steps to cope with the current outbreak therefore, the confirmed cases, and the mortality rate is less in Pakistan as compared to some other developed countries. But now the cases are increasing day by day. The research these days regarding COVID-19 is in progress and initial stage so it was important to write a correspondence and make some contribution in controlling the COVID-19 pandemic.

Nosocomial infection, foodborne disease, and outbreaks are associated with high voltage hospitalization as well as the economic losses every year, and millions of deaths are reported [1]. COVID-19 arose in Wuhan, China in late December 2019 [2], which spread very rapidly worldwide [3]. To minimize the risk and impact of such scenarios to control the outgoing outbreaks and pandemic certain precautions and preventative measures should be applied. Among these one of the most important steps is to detect the pathogen. The outbreak can be controlled by the detection of the pathogen within the short period that is in an early stage can minimize the risk of outbreaks. On the spot detection with a short time by designing a biosensor will be reliable. The antibody base detection and other classical and molecular base technique are expensive and need several days which some time leads to the severity of outbreaks and infection. To avoid such a circumstance, we must design a special and sophisticated biosensor which can detect the pathogen within no time. The advancement in medical research still has difficulties to handle with the novel pathogen in epidemics. So, to avoid all these we should target to detect the integral and structural component of the pathogen for detection and after that, we can take some preventative measures and further go for molecular detection. It is still a great demand to design a biosensor for pathogen detection which has novelty in their features.

\section{Role of psychology}

In the modern era, medical science is still struggling to find out the solution to overcome stress and different kind of training and classes and seminars are arranged in every country to overcome depression and broadspectrum tranquilizers are using worldwide. Meanwhile, the rate of stress and a body already overloaded with a chemical mediator can easily be depressed and let make your body more susceptible to infectious disease. The study proves that psychologically strong and positive people have a strong immune system and working properly as compared to depressed people. The people living in urban and hilly areas sometimes don't believe such a phenomenon and they mostly recover earlier as compared 
to the people who almost know what infection is? The reason is, the immune system is not distributing and easily encounter the pathogens. Another naked-eye observation is the children from a poor family and rich family where there the immunity which is acquired immunity he developed during when he is playing on the ground or sometimes, he exposes to birds and animals which they have in their own houses. The psychology that is strong psychology can play a crucial role in the control of COVID-19 up to some extent.

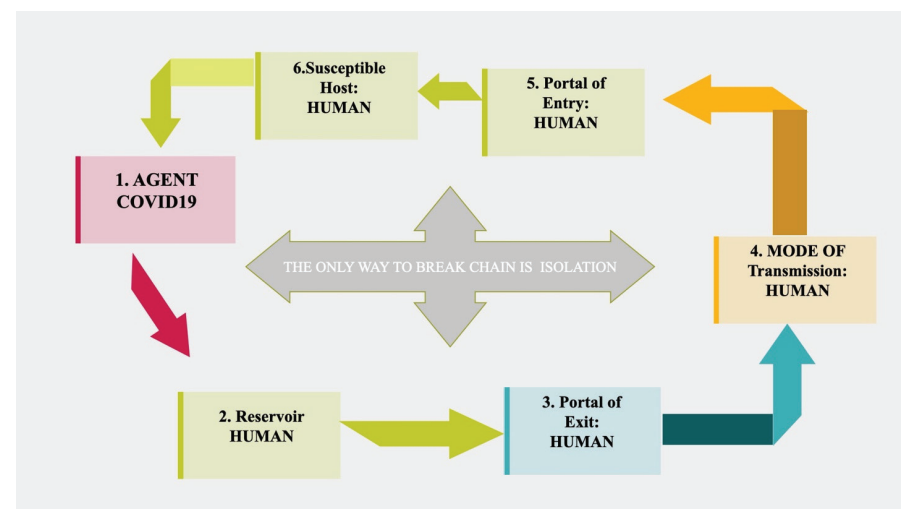

Figure 1 - Chain infection of COVID-19.

\section{Social norms}

As we are living in communities where we cannot avoid such sort of activities. These are the customs which are considered the part of the culture and without any discrimination of religion and other factors, people are participating and take part in such kind of activities. But in the control of infectious disease where it is very important to break the chain of infection to control disease, it is very important to control such activities because the reservoirs here is the person living in society. Such precaution proves very helpful in the control of COVID-19 in china as they sacrifice all their social norms and festivals, and they were limited to their houses and for several months they have no personal contact with their relatives. To keep in mind the severity of the infection one should compromise all these factors which are the very first step to break the chain of infection and very limited time we can control the disease in a short period.

\section{Religious activities}

Mostly the religious activity is carried out in the aggregations which evaluate the rate of transmission of infectious and contiguous infections. With due respect mentioned here, most of the religious activity has a great influence on the rate of transmission of disease. As compared the rate of transmission of religious activity which is carried out in aggregations will have a great influence on the transmission of disease. In Muslim countries where women are limited to do the activities at home, the electronic media results show that the rate of infection in women is comparatively less as compared to men. 1400 years ago, a Prophet Muhammad (PBUH) quoted that they do not go to the place of pestilence (epidemic) and do not go out of the pace of pestilence. This quote can be applied in the current situation as "social distancing".

\section{Media}

As we are living in the modern era where the electronic media and social media is need of the day. But this portion of the society has two different aspects one is positive which is not possible and the other is negative aspects. This is the line that can play a very important role in the control of COVID19 if there is proper management. As mentioned by [4] everyone has freedom of speech, this is why the media plays a very irresponsible role. In the current situation, media sources can play to reduce the panic condition [5]. Most of the channel news everyone knows is doing business which is not the part of humanity and they just spreading fake news which leads to a very bad impression and has a bad impact on health as we early mention. A suggestion is to block the channels which are not registered and propagate such news. Social media must completely block because most people there just earn money and they are considering a private sector that must be under the control of the government.

Disclosures: There is no conflict of interest for all authors. Acknowledgements: None Funding: None.

Authorship statement: All the authors have made a substantial contribution to the current study conception, drafting, and final version with an agreement to be accountable for the work.

Ethical Approval: Ethical approval is not required as this is correspondence paper.

\section{References}

1. Ford-Jones EL, Wang E, Petric M, Corey P, Moineddin R, Fearon M. Hospitalization for community-acquired, rotavirus-associated diarrhea: a prospective, longitudinal, population-based study during the seasonal outbreak. Archives of pediatrics \& adolescent medicine. 2000; 154(6):578-585. Chttps://doi.org/10.1001/archpedi.154.6.578.

2. Kelvin AA, Halperin S. COVID-19 in children: the link in the transmission chain. The Lancet Infectious Diseases. 2020; https://doi. org/10.1016/S1473-3099(20)30236-X.

3. Meyer JP, Franco-Paredes C, Parmar P, Yasin F, Gartland M. COVID-19 and the coming epidemic in US immigration detention centres. The Lancet Infectious Diseases. 2020; https://doi.org/10.1016/S1473-3099(20)30295-4.

4. Latif F, Bashir MF, Komal B. Role of electronic media in mitigating the psychological impacts of novel coronavirus (COVID-19). Psychiatry Research. 2020; 113041. https://doi.org/10.1016/j.psychres.2020.113041.

5. de Wit L, van Straten A, Lamers F, Cuijpers P, Penninx B. Are sedentary television watching and computer use behaviors associated with anxiety and depressive disorders? Psychiatry research. 2011; 186(2-3):239-243. https://doi.org/10.1016/j.psychres.2010.07.003. 